\title{
El ojo infecto de la televisión. A propósito de Riget de Lars von Trier
}

\author{
Laura Odello
}

Riget, la serie de televisión de dos temporadas dirigida por Lars von Trier entre 1994 y 1997, pone en escena un hospital acechado por fantasmas y una comunidad científica atrapada por sus propias supersticiones. Guiada por esta serie el artículo explora la contaminación de la mirada médica así como la contaminación de los ojos de los espectadores. Al reflexionar sobre la práctica de la autopsia, Foucault describió la mirada médica como ver la vida a través del espejo de la muerte, el "gran analista" que hace posible entender y describir la enfermedad. Pero es sobre todo la noción de Derrida de autoinmunidad la que permite pensar la mirada como algo que ya estaba permeada por otro ojo - un extranjero, un extraño, un elemento ominoso que infecta nuestra visión mientras que es, a su vez, su propia condición de posibilidad.

Palabras Clave: Lars von Trier, Riget, infección, muerte, Derrida.

Riget, the two-season television series directed by Lars von Trier between 1994 and 1997, stages a hospital haunted by ghosts and a scientific community beset by its own superstitions. Guided by this series, the article explores the contamination of the medical gaze as well as the contamination of the beholders' eyes. Reflecting on the practice of autopsy, Foucault described the medical gaze as seeing life through the mirror of death, the "great analyst" that makes it possible to understand and describe illnesses. But it is above all Derrida's notion of auto-immunity that allows us to think of the gaze as already pervaded by another eye - an alien, strange, and uncanny one, infecting our vision while also being its very condition of possibility.

KEYWORDS: Lars von Trier, Riget, infection, death, Derrida. 
Fecha de recepción: 2 de septiembre de 2013

Fecha de aceptación: 30 de septiembre de 2013 


\section{Laura Odello}

Collége International de Philosophie, Paris

\section{El ojo infecto de la televisión.}

\section{A propósito de Riget de Lars von Trier ${ }^{1}$}

Traducción: Esther Cohen y María Ordóñez Cruickshank

\section{A modo de epígrafe dos escenas}

La primera extraída de Quarantine 2: Terminal. Una película de terror realizada en el 2011 por John Pogue, que nos cuenta la historia de una epidemia en un aeropuerto, donde las personas se transforman en muertos vivientes deseosos de sangre. Al final de la película, el único sobreviviente será un joven muchacho que logra escapar de la terminal utilizando un túnel que puede recorrer gracias a la visión nocturna de su cámara de video. Habiendo salido al aire libre, abandona la cámara y se aleja sano y salvo. La cámara, fija en el suelo, continúa filmando. La imagen borrosa graba el paso de un gato contaminado, que se sacude salpicando de este modo el objetivo. Este, rociado con el líquido infecto, recobra automáticamente un cuadro enfocado: al fondo de la imagen, la ciudad está de ahora en adelante perfectamente nítida.

La segunda escena fue extraída de otra película de terror, Quarantine, realizada en el 2008 por John Erick Dowdle. En pleno reportaje,

${ }^{1}$ [N. del Ed.] Riget (The Kingdom) es una miniserie de televisión dirigida por Lars von Trier, director y gionista danés quien fue uno de los creadores del manifiesto Dogma 95. Entre su filmografía se encuentra Epidemic, Breaking the waves, Dancer en the dark y Dogville. 
Scott, un camarógrafo, se encuentra encerrado en un edificio que fue puesto en cuarentena debido a un virus extraño. Scott mata a un zombi golpeándolo con la cámara que continúa filmando la escena que nosotros mismos estamos observando. La cámara golpea al muerto varias veces, hasta rematarlo. A cada golpe, su ojo de vidrio se ensangrienta cada vez más. La mirada manchada de la cámara gira en círculos hasta hallar su reflejo en el espejo: ese ojo manchado, ensuciado con el líquido infectado, esa mirada mancillada se mira a sí misma en el espejo. Se contempla como infectada antes de que Scott la limpie; como un par de anteojos salpicados por la explosión hematológica que nubla la visión.

Imagino estas dos escenas las como una especie de cuadro, cuyo texto a continuación será un largo y sinuoso comentario. Ciertamente un análisis, pero siguiendo caminos desviados.

En efecto, ¿cuál es el problema que se plantea a partir de la imagen infectada?

"Es cuestión [...] del espacio, del lenguaje y de la muerte; es cuestión de la mirada" escribía Michel Foucault en su Naissance de la clinique (V).

El espacio será aquí el de un hospital. El lenguaje será el de la ciencia médica. Pero sobre todo, tratará sobre la mirada, la mirada puesta sobre la vida en tanto que acechada por la muerte. De la mirada, de la óptica o del ojo, de la autopsia por la cual la medicina, con sus propios ojos, con una visión propiamente médica, ha intentado encerrar y delimitar a la muerte, mientras que recurre a ella, para la vida, para salvar la vida, para hacer durar la vida.

A fin de cuentas, será algo como la vida-muerte con lo que deberemos contar.

\section{H}

Fantasmas que gritan, ambulancias sin chofer que circulan con sus sirenas resonantes, paredes que lloran sangre: esta es la decoración de Riget, literalmente le Royaume, miniserie de televisión que Lars Von Trier realizó en 1994 (primera temporada) y en 1997 (segunda temporada). Se dio a conocer como L'Hôpital et ses fantômes en las pantallas francesas. 
El tema del Royaume es más o menos el siguiente: en el gran hospital de Copenhague, verdadero templo de la ciencia médica, parece que algo misterioso sucede. Espíritus benignos y demonios diabólicos aparecen y regresan del pasado para atormentar el presente: historias de fantasmas errantes acompañan de este modo a intrigas amorosas, sesiones de espiritismo (inverosímiles) a operaciones quirúrgicas (verosímiles), embarazos monstruosos a trasplantes de órganos demenciales. Todo esto sucede con un estilo infeccioso, es una serie que te mantiene pegado a la pantalla de manera patológica y te crea una grave dependencia televisual. Un soap opera (telenovela) que se sitúa entre el terror y el melodrama cómico, en el que aparece el mismo tema de la infección, o el de la contaminación epidémica entre el bien y el mal, la salud y la enfermedad, el mundo científico y el mundo oculto, el reino de los vivos y el de los muertos.

\section{मै}

Verdadero protagonista de la ficción, el Riget — nombre popular del Righospitalet, el Hospital Real de Copenhague - se presenta como un cuerpo inválido y agonizante, auscultado por la cámara que diagnostica sus secciones enfermas. Un escucha interno en el hospital-cuerpo, donde el ojo de Lars von Trier, y por lo tanto el nuestro, se tiñe de un color que se aproxima al sepia y que parece imitar una sonda endoscópica, que examina y explora las paredes internas del cuerpo. Las recámaras donde los enfermos guardan cama, los quirófanos, la morgue, así como los sótanos laberínticos, los elevadores, los corredores, los suelos y paredes de esta gran catedral-nosocomio, pasan bajo el escáner fílmico como los miembros desgastados de un organismo que muere o de un zombi que cae en ruinas mientras se arrastra por inercia.

La salud del hospital es precaria, su historial clínico se anuncia desde el prólogo que abre cada episodio, como si se tratara de una especie de anamnesis patológica: aquí se revelan los antecedentes históricos, las primicias de una enfermedad que anuncian desde un principio su rápido declive. El Riget fue construido en el sitio donde antes se encontraba un viejo estanque palustre, que utilizaban los tintoreros para blanquear sábanas percudidas por el tiempo: la voz en off relata la histo- 
ria y las imágenes circulan lentamente mostrando un pantano invadido por la bruma, telas extendidas o flotantes que se blanquean, lavanderos que enjuagan una y otra vez las sábanas blancas. Con la construcción del hospital, la medicina y la investigación científica disolvieron la bruma, los doctores con batas blancas remplazaron a los lavanderos: "[...] para culminar su trabajo, lo llamaron el Royaume. Eran los amos de la vida. La ignorancia y la superstición ya no perturbarían los baluartes de la ciencia". La voz continúa su relato mientras que la cámara se hunde lentamente bajo el agua, siguiendo el movimiento de un lavandero que sumerge una sábana en el pantano. "La arrogancia y el desdén de las fuerzas espirituales duraron quizás demasiado tiempo. Ahora es como si el frío y la humedad hubiesen regresado. Las señales de cansancio comienzan a mostrarse en el corazón de este edificio moderno". Mientras tanto, la cámara se desplaza, continúa su movimiento hasta mostrar el fondo oscuro del pantano y se detiene. La voz concluye: "Ningún ser viviente lo sospecha siquiera, pero las puertas del Royaume están a punto de abrirse de nuevo". El sonido se vuelve aún más inquietante, dos manos salen del cieno y una cascada de sangre (a la manera de Kubrick) escurre por las grietas de una pared donde aparecen las letras de la palabra Riget, el Royaume.

\section{H}

En suma, el hospital no tiene el aire de estar bien y el cuadro clínico no promete nada bueno si uno se remite al prólogo, que parece anunciar, en el Royaume, una crisis inflamatoria inminente.

De hecho, de entrada y sin espera, la intriga se prende y arde. Sigrid Drusse - una paciente hipocondriaca y espiritista - entra en contacto con el fantasma de una niña que murió en el hospital en 1919, la pequeña Mary, muerta por una dosis letal de cloro administrada por su padre — el doctor Aage Krüger-, quien quería deshacerse de su hija ilegítima. El fantasma de Mary, reviviendo una y otra vez, todos los días, su muerte sacrificial que nadie puede atestiguar, ronda el hospital en busca de justicia y de sepultura. Pasando del reino de los muertos al de los vivos, nos encontramos, hoy en día, en contraste, con una niña que nos recuerda la injustica cometida contra Mary: Mona sufrió daños 
cerebrales irreparables debido al error del neurocirujano Stif Helmer, el arrogante vice-jefe de cirugía del hospital.

La intriga se vuelve más espesa y el hospital empeora su estado. El prólogo ya nos lo había prevenido. El Riget, verdadero mastodonte, yace sobre un pantano que fue desplazado, en el que un perjuicio que ha sido reprimido regresa para repetirse acechantemente, emerge desde el subsuelo para reclamar justicia. En el hospital, cada vez más enfermo, aparecen fisuras siniestras en las paredes, grietas que se abren en el piso y en la cañería, que comienzan a explotar por la presión del agua subterránea que aflora de nuevo, turbia e impetuosa. El pantano se mueve y hace que tiemblen los cimientos del hospital.

Hay algo putrefacto en el Royaume de Dinamarca. El Royaume, infestado de fantasmas, está infectado.

La señora Drusse, luego de enterrar el cuerpo de Mary, decide exorcizar su fantasma, para darle el descanso eterno que merece. Convence a su hijo Bulder, camillero del Reino, así como al doctor Krogshøj, para que le ayuden a encerrar al fantasma de Mary en el mismo lugar donde murió, y que de esta manera pueda encontrar la luz. Los exorcismos comienzan utilizando raquetas de tenis a manera de crucifijo para conjurar a los fantasmas atemorizados, espíritus que se manifiestan como ectoplasma baboso...

Pero hasta los doctores deben enfrentar la infección. En el corazón de la Logia secreta y fraternal del Royaume, uno de los doctores advierte a sus colegas: "Una infección se abrió camino al interior del organismo". Y, para poder salvarlo, los "glóbulos blancos", es decir los médicos fieles a la ciencia, deben ayudarse entre sí con el fin de extirpar al mal que se presenta bajo muchos nombres, desde el naturismo a la homeopatía, desde la medicina alternativa a la necromancia...

La Logia de médicos se prepara, entonces, para luchar contra lo oculto, las prácticas animistas y las supersticiones, "en resumen, todo aquello que no es ciencia y que no tiene ningún sentido". Los glóbulos blancos, los doctores, bajo el candor sagrado de sus batas, deben cerrar los flancos para sanar la lesión del organismo enfermo: pero para lograrlo, 
como le dice un doctor a sus compañeros de la Logia, primero hay que "confesar sus propias inclinaciones", las tendencias que uno conlleva en sí, develar el germen de lo oculto en uno mismo para poder purgarse.

Someterse por lo tanto a un lavado desinfectante para purificarse. Los doctores en bata blanca no paran de repetir, de recrear de manera espectral, el gesto purificador de los lavanderos que blanquean las sábanas sucias, con el afán de encontrar el blanco original, restaurar la pureza o, en otros términos, restablecer la inmunidad de su cuerpo. Un cuerpo que, antes de ser médico, es decididamente y esencialmente político. No solo porque en la archisecreta logia del Royaume los médicos se protegen los unos a los otros intercambiándose favores, sino también y sobre todo porque debemos tomarnos en serio las palabras de los médicos del Royaume, particularmente las que el profesor Bondo, sin importar que tan caricaturesco y patético sea, dice a sus alumnos a lo largo del curso de patología: "No tomar en serio a la patología significa no tomarse la vida en serio", afirma el patólogo, conmovido delante de un cadáver, delante de la generosidad extrema de un cuerpo que se ofrece en sacrificio por la ciencia, que se entrega a esta suprema y grandiosa comunidad, en la que acepta trabajar sin importar quién trabaje o se cure en el Royaume. La grandiosa comunidad de "la ciencia que nos pertenece a todos".

H

Debemos tomarnos en serio este discurso, pues es uno de los discursos filosóficos más poderosos de la tradición occidental, es aquel que construye una comunidad política al instituir una línea clara de demarcación que pretende separar y oponer la vida a la muerte. Aún mejor: identificar la vida como aquello que excluye, expulsa o veta a la muerte. ${ }^{2}$ Ya que

${ }^{2}$ No es casualidad que Platón, en la Política, no pare de convocar a lo largo del diálogo a la medicina, es decir, a una metáfora médica, para hablar del objeto mismo de lo político, a esta comunidad viva que se constituye al sanarse, al expulsar de ella misma las impurezas, así como (y aquí la metáfora) el médico cura la enfermedad, sana al cuerpo enfermo. Los que gobiernan, en efecto, gobiernan conformándose con un arte al igual que los médicos. Así como el médico, dice Platón, "no tiene ningún otro objetivo más que nuestro bien, el de nuestros cuerpos [agathoî toi tôn somatõn, el bien de los cuerpos], al hacerlos pasar de un estado peor a uno mejor" (Politique, 293b); de 
la comunidad política es una comunidad viva, comunidad de los vivos reunidos en su seno, que están relacionados entre ellos por esta, que están sanos y salvos, protegidos, defendidos por ella. Inmunizados en ella y por ella. ${ }^{3}$

La suprema y grandiosa comunidad se recoge y se reúne en ella y alrededor de ella misma, alrededor de su propia vida y vitalidad, justa y precisamente aquí, en el Royaume, en el corazón del reino de la ciencia. Esta ciencia que, como parece sugerir el profesor Bondo, se muestra seria frente a la muerte: la estudia, la descompone, la diseca en su anatomía. La separa de la vida, la mantiene bien separada de ella y la observa. La ciencia observa a la muerte con sus propios ojos (es más, esta es la etimología de la palabra autopsia: observar con sus propios ojos), la ciencia solo le cree a sus propios ojos, que son los más apropiados para vigilar a la muerte, para mantenerla siempre al servicio de la vida, para contenerla y mantenerla en el interior de un vaso de vidrio donde se le puede observar.

Insisto: realmente hay que tomarnos en serio las afirmaciones de Bondo acerca de la seriedad de la vida ("No tomar en serio a la patología significa no tomarse la vida en serio"), acerca del destino grandioso y supremo de una comunidad científica cuyo saber significa el poder soberano sobre la muerte; el dominio soberano sobre la muerte; la ciencia es la vida, es el saber vital que domina a la muerte. Si combate a la superstición, al ocultismo y a la fe en lo paranormal, en los fantasmas y los muertos que regresan, si intenta protegerse, de indemnizarse de la infección de las artes ocultas que corren el riesgo de disgregar a la comunidad científica, la cofradía de los vivos y todas las otras logias de la racionalidad logocéntrica, es precisamente para conjurar su regreso, la resurrección de esta muerte que tuvo que expulsar para constituirse. Esta muerte que la patología de Bondo reduce al sacrificio supremo de

\footnotetext{
la misma manera en la que un médico salva nuestro cuerpo curándolo, el que gobierna, el hombre político, salva nuestro cuerpo del Estado. A la vez que se inspira en el conocimiento, en el justo conocimiento, dicho de otra manera en la justicia, lo cura, lo vuelve mejor.

${ }^{3}$ La comunidad es la inmunidad misma, la inmunidad que unifica, que hace la unidad de la vida, el interiori vital de uno, de uno como el mismo. Inmunidad como comunidad, co-inmunidad, como pudo decirlo Derrida.
} 
un cadáver esterilizado, inofensivo y disecable, al someter al bisturí a una ciencia pura y a la vigilancia de unos ojos siempre atentos, verifica y comprueba que el muerto esté muerto, realmente muerto, y que no haya otra manera de pensar la muerte sino como aquella que excluye completamente a la vida.

Ya lo he dicho: los doctores con batas blancas no paran de repetir, de recrear de manera espectral el gesto purificador de los lavanderos que blanquean las sábanas sucias, buscando reencontrar de esta manera el blanco original, desinfectarse para restablecer la pureza o, en otros términos, restablecer la inmunidad de sus cuerpos, el médico y el político.

¿Qué quiere decir, desde entonces, restablecer la inmunidad, la pureza y la blancura de este cuerpo comunitario, sino conjurar a los fantasmas que lo acechan? Si la vida de la comunidad tuvo que constituirse sacrificando en ella misma a la muerte, matando a la muerte, entonces qué otra cosa podría significar el sueño de un lavado o blanqueamiento absoluto sino alejar la mirada, voltear la mirada, es decir no querer ver el gesto violento de matar a la muerte que constituyó de manera sacrificial la vida misma de la comunidad. ¿Qué puede ser esta blancura, sino una conjuración supersticiosa contra toda infección de la vida misma, de la ciencia médica y de su cuerpo? Una conjuración de fantasmas que acechan al cuerpo inmunitario de la ciencia, superstición...

Sin embargo nosotros, en el fondo, no estamos tan alejados del exorcismo de Madame Drusse; es por el contrario muy familiar. Incluso el profesor Helmer parece saberlo, él que en uno de los primeros episodios acusa a la adorable anciana de fingir, de ser una falsa mística, una enferma imaginaria que engaña a los médicos al citar manuales de neurología para llamar su atención.

Como si el espiritismo no fuera entonces más que una falsa copia, un duplicado, un facsímil corrompido por la práctica médica. Ya que al disputar el lugar privilegiado de la salud ellos son mucho más solidarios de lo que parecen: no solamente Madame Drusse será invitada a una reunión de la logia del Reino para aconsejar a los cofrades sobre la manera de luchar contra lo demoniaco que se propaga en el hospital, sino que, por otra parte, esta loca Miss Marple de los espíritus, se arroga la responsabilidad de remediar los males del Reino, a fin de dulcificar y sanar "la herida" del hospital. En cuanto a la relación es- 
pectral entre medicina y ocultismo será no obstante el doctor Kroshøj quien hará la mejor réplica en respuesta a un colega que le pregunta si tiene un minuto: "Imposible, hoy tengo que hacer un exorcismo y una operación".

La superstición parece entonces haber regresado al Royaume, donde, si le creímos al prólogo, la medicina parecería sin embargo ya haberla desechado. Rechazada, renegada, repudiada, la superstición regresa como esos fantasmas que vuelven a exigir justicia. Justicia por una intervención quirúrgica fallida - como la de Mona o la de Mary, de las que se quiere borrar las huellas, pero también y sobre todo como justicia por la operación archi-quirúrgica que extirpó del cuerpo del saber científico al mal de la prácticas animistas, de lo oculto, y que regresa a acecharla con sus métodos impuros, a infectarla con sus exorcismos. Una operación archi-quirúrgica que precede a la cirugía misma y que es tan solo la repetición mimética: operar para curar y sanar habrá siempre querido decir que la ciencia médica ya está intervenida quirúrgicamente para extirpar al mal que la amenaza, "todo aquello que no es la ciencia". La ciencia médica no es lo que es sino después de esta operación y gracias a ella, no antes ni a pesar de ella.

Si es así el rechazo del reino, del reino de la ciencia, del reino como ciencia, este rechazo no debe ser solo y simplemente comprendido como rechazo de la muerte sino como un rechazo inapropiado de la diferencia que lo constituye. Ya que el Royaume se funda en la exclusión de esta diferencia a partir de la cual se constituye: se plantea, se configura en tanto que este rechazo. En otros términos, la ciencia está, ya y desde siempre, inscrita en esta exclusión que sin embargo ella quisiera dominar, que sueña con poder producir mientras que ella no es más que un efecto de este reenvío diferencial y excluyente.

Mientras tanto el Reino, cada vez más infectado, es examinado por unos ojos maléficos: una mirada verduzca y temblorosa parece insinuarse en cada pliegue de su cuerpo enfermo. Alguien o algo observa el hospital. ¿De quién son esos ojos?, pregunta Madame Drusse al fantasma de Mary, que no responde. 
Hay alguien en el Royaume que con la intención de preservar y proteger la ciencia no trata de vencer la infección, sino por el contrario la alimenta y la nutre con su propio cuerpo. Llegando a introducirla en ella. Se trata del profesor Bondo, el patólogo que lleva a cabo la autopsia, como el momento supremo de la ciencia en la que la muerte es vista con sus propios ojos (según la etimología de la palabra autopsia). Este anatomopatólogo que declara a sus estudiantes que "el curso de nuestras vidas está escrito en el ADN [...] y que no hay nada que no pueda comprenderse, nada que no puede verse a través de nuestros propios ojos", y bien, se hará trasplantar el hígado enfermo de un muerto. Alguien comenta: "El hombre que corta a los muertos tiene un pedazo de hombre muerto en el vientre".

Frente a un paciente afectado por un enorme hepatoma, un tumor maligno del hígado de dimensiones extraordinarias, Bondo trata de convencer a la familia del moribundo para que autorice la autopsia después del deceso. Ya que, explica, él espera desde hace diez años un caso parecido para lograr sus investigaciones. La familia se niega y Bondo está desesperado. Después de haber intentado un último recurso entre sus colegas de la logia ("ayúdenme a ayudar a la ciencia" dijo), él piensa, desde entonces, que ya que el paciente ha aceptado el trasplante de órganos, él mismo podría hacerse trasplantar el hígado enfermo en su propio cuerpo. Al menos durante algunos minutos, justo el tiempo necesario para poder declarar que el órgano es suyo, para que se convierta en su propiedad. Sin embargo, algo no marcha bien y el hepatoma quedará en su cuerpo más tiempo. Sus condiciones físicas van a empeorar pero Bondo, orgulloso de haber hecho crecer en él el más grande hepatoma del mundo, rechazará un nuevo hígado...

El hombre que corta a los muertos tiene un pedazo de hombre muerto en su vientre. El cuerpo de Bondo se convierte en un verdadero laboratorio de análisis clínicos, el lugar por excelencia de la autopsia. Es él mismo el que se convierte en el instrumento de su propia autopsia. Un instrumento "auto-óptico", podríamos decir, para analizar mejor y disecar a la muerte, para poder separarla mejor de la vida. Bondo incorpora en sí mismo la infección de un cadáver para hacer triunfar la vida misma de la ciencia, la vida como ciencia o la ciencia como vida. Es decir, su poder soberano sobre la muerte. Para coronar el sueño científico de 
una vida inmune contra la muerte, Bondo alberga en su interior este elemento de muerte que la autopsia pretende aislar y neutralizar. Pero este pedazo de muerte introducido y cultivado en el cuerpo, este tejido necrótico, infiltrado en el corazón de la vida es también lo que infecta y corre el riesgo de destruirla. La vida y la muerte parecen entonces contaminarse, infectarse la una a la otra. Y desestabilizar la línea que pretende separarlas, de la misma manera que ella pretende definir los márgenes y los contornos de la mirada de la "autóptica".

El hombre que corta a los muertos tiene un pedazo de hombre muerto en el vientre. El hombre que hace las autopsias, aquel que mira con sus propios ojos los cadáveres se convierte en un instrumento "autoautóptico".

Pero si el cuerpo vivo del patólogo se convierte en el cuerpo mismo de la autopsia, de una autopsia de cuerpo vivo, ¿qué pasa aquí con la mirada médica?

Podríamos plantear la hipótesis de que lo que esta mirada ve, lo que mira con sus propios ojos es finalmente la muerte, es decir la muerte actuando en la vida. La muerte a la que, como dice Foucault, la medicina, gracias a su mirada médica que acabo de calificar como autóptica, comienza a pedirle cuentas a la vida, a pedirle cuentas por la vida. En efecto, en Naissance de la clinique, Foucault nos dice que los médicos han volteado los ojos siempre hacia la muerte ya que ella era "este hecho a partir del cual no hay ni vida ni enfermedad" (143). Con la muerte no hay vida, no hay más enfermedad. Y este presupuesto (de una muerte que excluye la vida y la enfermedad), la experiencia clínica, nos dice todavía Foucault, no ha sido capaz de ponerlas de nuevo en cuestión antes de ese gran cambio de paradigma que representa la mirada anatomo-patológica. Entonces, antes de la práctica médica de las autopsias, a partir del siglo XIX, es decir, antes del corte de los cadáveres. "Abre algunos cadáveres, como decía Bichat: 'verán enseguida desaparecer la oscuridad que la sola observación no había podido disipar'” (149).

La gran revolución médica del siglo XIX, nos dice Foucault, está constituida por la teoría anatomo-clínica, es decir, por la medicina de los tejidos y de los órganos que remplaza la medicina de los síntomas. El síntoma debe ser ahora estudiado en profundidad, es necesario estudiarlo en el mismo cuerpo y la autopsia se convierte en un medio que 
permite descubrir la verdad de lo vivo. La medicina se dirige así hacia la muerte: Bichat definía incluso la vida misma como "conjunto de funciones que resisten a la muerte". Es ahora a partir de la muerte cuando se analiza, cuando se estudia la vida. Las autopsias, las disecciones de cadáveres hechas inmediatamente después de la muerte permiten distinguir entre los procesos mórbidos y los procesos de dirección hacia la muerte: la muerte no es más una ruptura brusca, sino una desaparición lenta y sucesiva de funciones vitales, que permite hacer aparecer la brevedad de lo vivo. Ella (la muerte) se convierte en la condición de posibilidad del saber médico.

Entonces, Bichat escribe: “Abran algunos cadáveres. Ustedes, durante veinte años, de la mañana a la noche, a los pies de la cama del enfermo, habrán tomado notas sobre las afecciones del corazón, de la víscera gástrica, todo será para ustedes confusión de los síntomas que, sin relacionarse con nada, les ofrecerán una serie de fenómenos incoherentes. Abran algunos cadáveres: verán desparecer la oscuridad que la sola inspiración no pudo haber disipado". Foucault concluye: "La noche viviente se disipa en la claridad de la muerte".

Con el corte de los cadáveres, con el corte del saber de la muerte, la mirada del saber médico cambia: A partir del siglo xix la medicina, apoyándose en el aparato técnico y conceptual de las autopsias, ve con los ojos de la muerte, mira la muerte que trabaja la vida. La mirada médica no es más la de un ojo viviente, esta se convierte "en la mirada de un ojo que ha visto la muerte", "el gran ojo blanco que desenreda la vida" (Foucault, Naissance de la clinique, 147). La muerte se convierte así en "la gran analista", "que muestra las conexiones desplegándolas y hace estallar las maravillas de la génesis en el rigor de la descomposición".

La muerte es de ahora en adelante lo que hace posible el análisis de la enfermedad, es esta gran analista a la que la medicina exige la razón de la vida y de la enfermedad: con Bichat y la práctica de la autopsia la mirada médica mira la vida a través del espejo de la muerte ${ }^{4}$ (Foucault, 147).

4 "El análisis de la enfermedad no puede hacerse sino desde el punto de vista de la muerte — de esta muerte a la que la vida resiste por definición. Bichat relativizó el concepto de muerte, haciéndolo caer de este absoluto donde aparece como un acontecimiento indivisible, decisivo e irrecuperable: lo ha volatizado y repartido en la vida bajo 
Me pregunto a propósito de Bondo, del hombre que corta a los muertos y que tiene un pedazo de hombre muerto dentro de sí: si el cuerpo viviente del patólogo se convierte en el cuerpo mismo de la autopsia, de una autopsia en el mismo cuerpo viviente, ¿qué pasa aquí con la mirada médica?

Hemos sugerido la hipótesis de que esta mirada que ve lo que mira con sus propios ojos, es finalmente la muerte, es decir la muerte actuando en la vida. La muerte a la que, como dice Foucault, la medicina gracias a su mirada médica que acabo de definir como autóptica empieza a exigir cuentas de la vida y por la vida.

Pero podríamos también seguir otra pista decididamente más radical, sobre la que nos habrá puesto Jacques Derrida: la de la autoinmunidad.

Foucault mismo reconoce que antes del corte de los cadáveres, la muerte era percibida por la medicina como la gran amenaza frente a la cual el médico no tenía ningún poder, frente a la cual su mirada se detenía. Deberíamos pensar aquí que la muerte que, como la hemos visto, constituye y hace posible la mirada médica, esta muerte que amenaza es precisamente lo que también salva. Ya que la vida y la muerte se contaminan, se infectan la una a la otra, y desestabilizan esta línea que pretende separarlas así como ella pretende definir los márgenes y los contornos de la mirada autóptica. Bondo, que ilustra la mirada autóptica por excelencia, se ha convertido ahora en el cuerpo que al mismo tiempo acoge la infección para estudiarla. Entonces, la mirada vital y objetiva de la medicina que Bondo encarna, este ojo autóptico está contaminado. Todo pasa como si el ojo autóptico de la ciencia tuviera necesidad de la muerte para constituirse en tanto que ojo viviente: la mirada médica, al incorporar la muerte y la infección para estudiarlas mejor, se infecta, se autoinfecta a través de lo que alimenta su vitalidad y su vigor.

A través del gesto de Bondo, la ciencia del Royaume parece estar en peligro. “iLos médicos están del lado bueno del bisturí y ahí se deben quedar!", protestará Helmer, al acusar a Bondo de poner en peligro la

la forma de muertes en detalle, muertes parciales, progresivas y muy lentas en concluirse más allá de la misma muerte" (149). 
credibilidad misma de la profesión médica. El Royaume, infectado, no será más el mismo. O mejor dicho será el mismo como otro.

Vida como muerte, por lo tanto, el yo como otro: tal es, parece, el punto ciego de la mirada autóptica, la vibrante mancha verduzca de los ojos maléficos que nos vigilan en la disimetría absoluta e inapropiable de una mirada que se hace imposible. En el corazón de nuestro ojo, otro ojo - impropio, extraño, inquietante - infecta nuestra visión, haciéndola sin embargo posible. La mirada del otro, del yo como otro, mirada de ese todo otro que somos nosotros mismos y que habita, acogido como un virus infeccioso, nuestros propios ojos.

Esta mirada de todo lo otro que ya nos ha mirado antes de que nuestra mirada se produzca y para que se produzca, puede llamarse una mirada de muerte. Verrà la morte e avrà i tuoi occhi. "Vendrá la muerte y tendrá tus ojos", como lo dice Cesar Pavesse.

Verrá la morte e avrà i tuoi occhi, ya que la muerte es siempre lo que llega del otro, como otro, sea el otro en sí, el yo como otro. La muerte es siempre lo que trae la vida.

\section{H}

Pero entonces estos ojos maléficos que nos analizan, inquietantes y verduzcos son probablemente los nuestros. Es nuestra propia mirada la que está infectada, la que se autoinfecta, porque ya desde siempre está infectada por el otro en sí. Somos nosotros el ojo monstruoso del Royau$m e$, este ojo que no mira y que no llegamos a ver ya que precede, mucho antes que nosotros, nuestra visión misma. Este ojo infectado en el corazón de nuestra mirada, esta marca verduzca que la mancha, que la persigue, no es otra más que la inscripción indeleble e indescifrable del signo inmemorial del otro, la marca desposeída de su infección. Como una $\mathrm{R}$ rodeada de un círculo $(\mathbb{R})$ : marca del otro, desposeída y registrada por el otro que nos recuerda que ella estuvo ya ahí desde siempre. Signo que marca la incisión y la inscripción del otro en nosotros, antes de nosotros.

Las puertas están abiertas de ahora en adelante de par en par y el $R o$ yaume (como el royaume de no importa qué experiencia o qué texto) se muestra vulnerable y revela una falta de poder en el corazón del poder: 
royaume sin soberano marcado por la memoria del otro, por la cicatriz de una infección que ya sucede siempre, cada vez que tiene lugar algo como un royaume - por ejemplo, cada vez que la imagen es imagen, cada vez que ella está en su casa en su propio royaume.

El Royaume abre sus puertas de par en par hacia el interior, hacia ese lugar desde donde se expande el contagio y donde se deposita la marca misma de su exterioridad. El Royaume está infectado, por lo tanto todos los royaumes o todos los textos lo están. Pero su enfermedad es el síntoma de una sana vulnerabilidad, sana quiere decir patológica, sana en cuanto patológica. Expuesto a la infección del otro - del mismo como otro - como debe estarlo necesariamente: si un Royaume, sin importar cuál sea, aún puede llegar, es solamente a condición de que se inscriba en la memoria misma de su vulnerabilidad constitutiva, de su vocación a la hospitalidad, en la repetición o reinscripción de la marca del otro, desde siempre depositada y registrada en el corazón o en su mismo reino.

\section{A manera de dedicatoria, una última escena}

Extraída de otra película de Lars von Trier, Epidemic (1987), la escena muestra esta inscripción en el corazón mismo del cuerpo fílmico, esta marca infecciosa del otro que acecha nuestra mirada autóptica. Epidemic está construida alrededor de una doble narración, de una historia inmersa en la otra: dos guionistas escriben el escenario para un film $\mathrm{y}$, como una película dentro de una película, este escenario cobra cuerpo al narrar cómo un médico, a partir de una epidemia, es empujado a abandonar la seguridad de su pueblo y de su propia comunidad para ir a curar a otras personas. Por lo tanto será él quien, sin saberlo, desencadenará la epidemia y llevará la muerte a aquellos a quienes quiere salvar. Este médico está contaminado por su deseo de profilaxis, es ciertamente la figura ejemplar de esta autoinmunidad de la que no nos hemos ocupado aquí, pero el film hace también otra cosa: muestra la autoinmunidad misma de las imágenes.

Los dos guionistas escriben la historia de una epidemia fatal que, al final de la película, se volverá realidad, es decir que pasará también so- 
bre el plano de la narración primera, donde todos los personajes mueren realmente. Y a la vez que escriben la historia, la epidemia se inscribe en las imágenes mismas dentro del mismo film, como lo muestra el logo rojo que está marcado sobre la película en tanto que signo de su propia infección. En letras rojas, la palabra EPIDEMIC se imprime sobre el carrete de la película: la epidemia marca al film con su huella.

La infección se marca, y quedará marcada sobre las imágenes, produciendo - y he aquí el efecto autoinmune suplementario - la infección misma del film. Esta marca roja que imprime el carrete de la película es precisamente la inscripción infectada e infectante en el corazón mismo del cuerpo fílmico. Ella es la que marca la infección en la historia y al mismo tiempo la historia como infección. Las imágenes, en síntesis, se producen autoinmunisándose, es decir dejándose infectar por ellas mismas.

El film queda así infectado. El film, es decir la historia de un film que narra la historia de una infección, se deja infectar por él mismo como otro: se deja infectar por esta otra historia, esta historia otra que es finalmente la misma. La misma infectada por la otra. La misma que se autoinfecta.

\section{REFERENCIAS}

Foucault, Michel, Naissance de la clinique, Paris, Presses Universitaires de France, 1963. 